\title{
Compression Fracture: Identify the Diagnosis
}

\section{Sarjoo M. Bhagia, MD*, Evan S. Siegelman, MD**, Russel V. Gilchrist, DO* and Curtis W. Slipman, MD*}

A 33 year-old male presents to the emergency room with complaints of severe chest pain. Myocardial infarction was excluded, but a compression fracture of the T5 vertebra was revealed on initial radiography (Fig. 1). The patient denied trauma, but did have a two-month history of insatiable thirst and generalized weakness. Diabetes was excluded by his primary care physician. Physical examination revealed tenderness to percussion over the T5 spinous process. Erythrocyte sedimentation rate and white cell count were normal. Magnetic resonance imaging (MRI) of the thoracic spine was obtained (Fig 2). What is the differential diagnosis?

\section{DISCUSSION}

$\mathrm{X}$-rays of the thoracic spine reveal collapse of the T5 vertebra (Fig. 1). MRI of the thoracic spine shows collapse of the T5 vertebral body with abnormal signal intensity on both the $\mathrm{T} 1$ and $\mathrm{T} 2$ weighted images. There is no spinal canal encroachment, cord compression or paraspinal soft tissue mass. The disk spaces appear normal (Fig. 2).

Compression fractures occur commonly in the elderly population. It has been estimated that $44 \%$ of women over the age of 70 have compression fractures (1). The

From Penn Spine Research Group, University of Pennsylvania Health System, Department of Rehabilitation Medicine, Philadelphia, Pennsylvania. *Dr. Bhagia and Dr. Gilchrist are fellows at the Penn Spine Center. ${ }^{* *}$ Dr. Siegelman is an associate professor of radiology and chief of the MRI section of the University of Pennsylvania Health System. "Dr. Slipman is the director of the Penn Spine Center, associate professor of the Department of Rehabilitation Medicine and Chief of the Clinical Musculoskeletal Program. Address correspondence: Curtis Slipman, MD, 3400 Spruce Street, Ground Floor White Building, Philadelphia, PA 19104.

E-mail: slipman@mail.med.upenn.edu

Funding: No financial support was obtained in the preparation of this manuscript. highest frequency of spinal compression fractures occurs at the thoracolumbar junction (2). The presence of compression fractures in young persons and/or in areas other than the thoracolumbar junction should raise a suspicion of trauma, osteomyelitis or an infiltrative neoplasm causing a pathologic fracture (3).

Traumatic compression fracture of the spine in a young individual is usually associated with a vertical fall resulting in axial compressive forces along the spine. The most common area of involvement is at the thoracolumbar junction. Imaging would reveal the compressed vertebral body along with a potential evidence of paraspinal hematoma, displaced bony fragments and kyphotic deformity of the spine. Our patient does not give any history of trauma.

Infection is a diagnostic possibility, although history and examination do not support this diagnosis. Infections of the spine are usually associated with intense throbbing pain, severe paraspinal muscle spasm, constitutional symptoms and an elevated erythrocyte sedimentation rate and white cell count. Infection of the spine typically occurs via hematogenous spread to adjacent vertebral bodies in accordance with the blood supply of the vertebrae, where each segmental artery supplies two adjacent vertebrae. The avascular intervertebral disc is subsequently infected by direct extension from the adjacent vertebrae. MRI can demonstrate abnormalities earlier than CT or radiography $(4,5)$. T1 weighted images demonstrate decreased signal in the vertebral bodies and involved disc and $\mathrm{T} 2$ weighted images reveal increased signal intensity due to increased water content. There is loss of disk height and varying degrees of bony destruction with absent or poorly demarcated cortical margins. Post-gadolinium images are helpful in differentiating an active acute inflammatory process from a chronic fluid collection. Infections of the spine are associated with epidural and/or paraspinal abscess.

Tuberculosis most often involves the thoracic vertebrae; however it has an insidious onset with symptoms progressing over months to years. There is widespread 


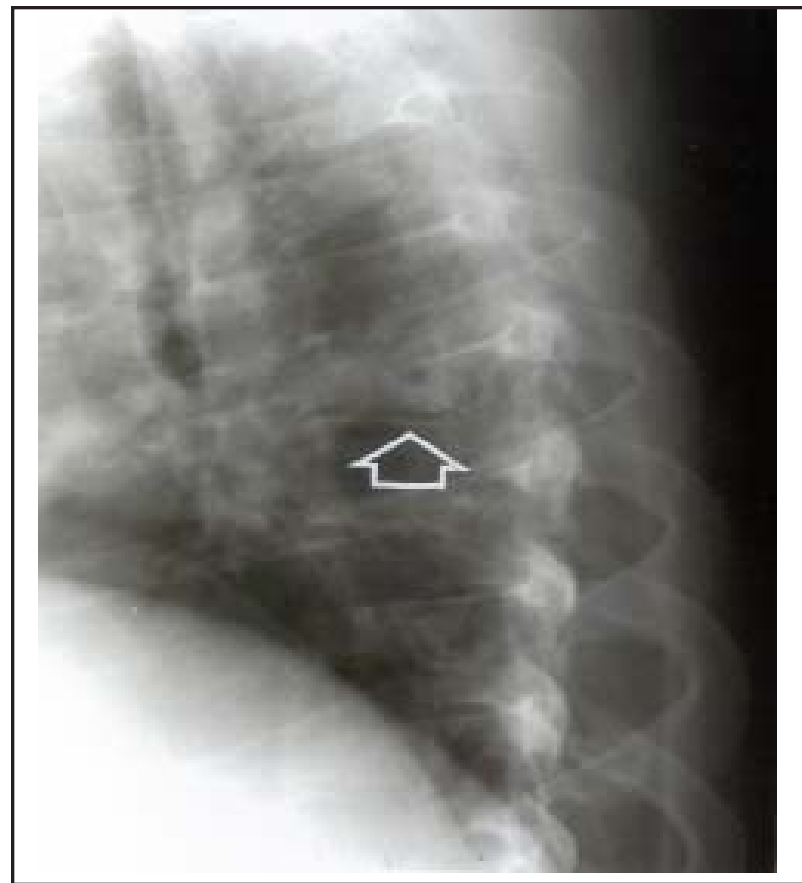

Fig.1. Lateral radiograph of the thoracic spine demonstrating collapse of T5 vertebral body

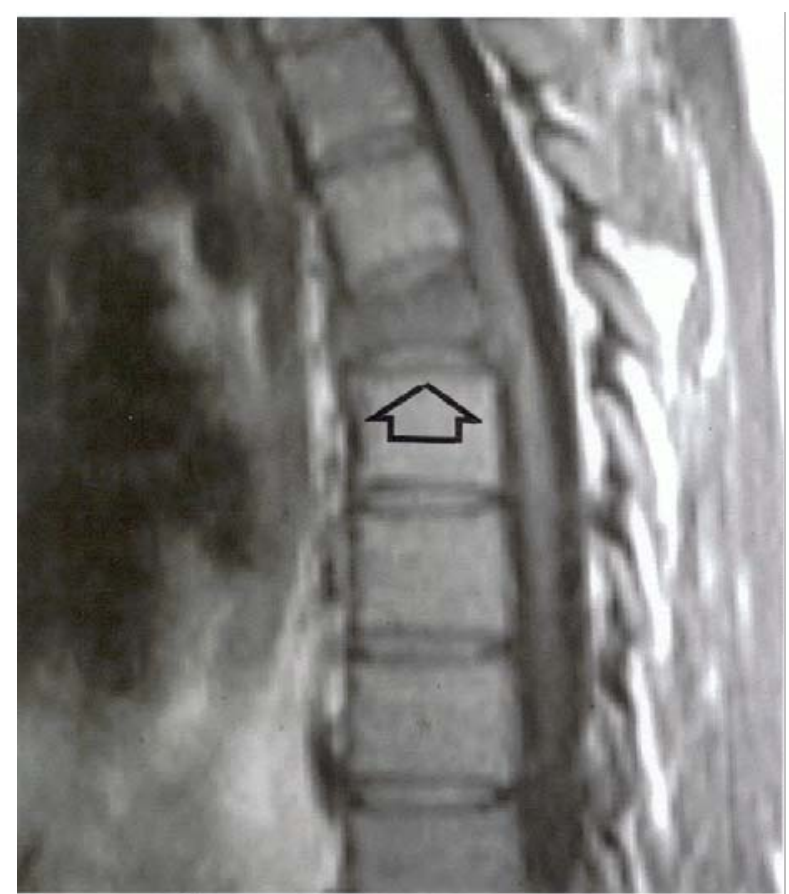

2a destruction of vertebral bodies with relative preservation of disk spaces. The anterior portion of the vertebral body is usually affected resulting in anterior compression and a kyphotic gibbous deformity. Skip lesions are present as infection spreads beneath the anterior longitudinal ligament to non-adjacent vertebrae. Psoas abscess is commonly associated with tuberculous osteomyelitis of the spine.

One should consider malignancy in the differential diagnosis of thoracic compression fracture. Malignant neoplasms include primary bone tumors, hematologic malignancy and more commonly metastatic disease. Malignancy can produce several patterns on MRI depending on the underlying malignancy. Lytic or destructive lesions such as multiple myeloma produce low signal intensity on T1 and high signal intensity on T2 weighted sequences. Blastic or sclerotic lesions such as metastatic prostatic carcinoma show low signal intensity on both $\mathrm{T} 1$ and $\mathrm{T} 2$ weighted sequences. Infiltrative marrow processes such as leukemia and lymphoma produce homogeneous decreased signal intensity on T1

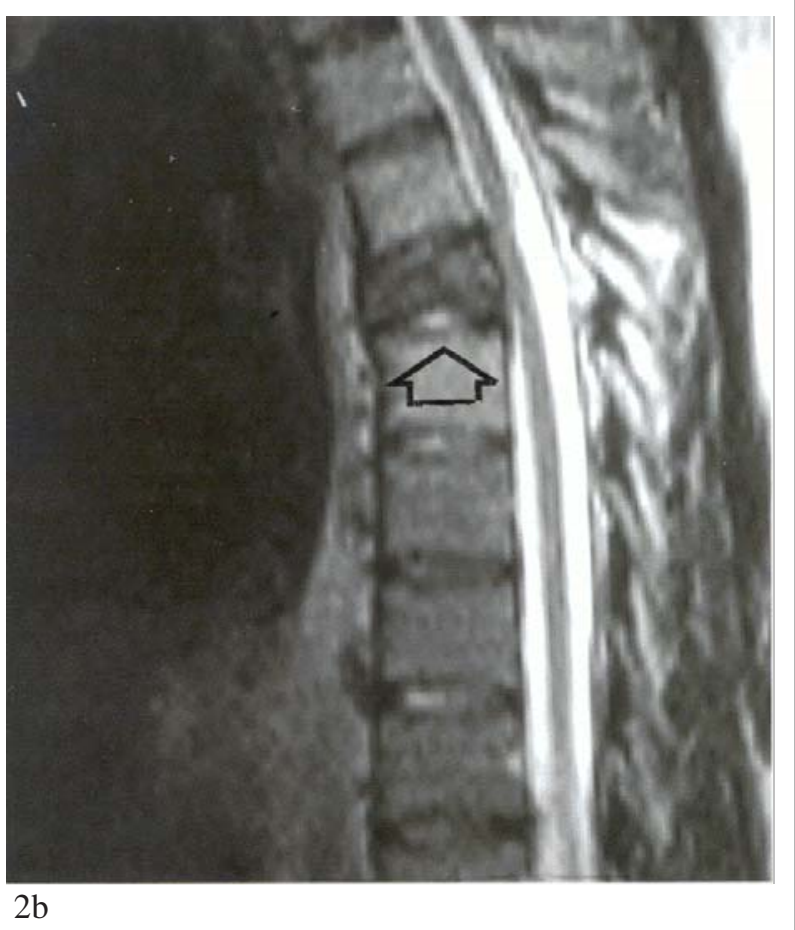

Fig. 2a. Sagittal T1-weighted spin echo (SE) and Fig. 2b. T2-weighted SE MR images of the thoracic spine showing loss of height of the T5 vertebral body which shows low to intermediate signal intensity on T1-weighted images and intermediate to high signal intensity on T2-weighted images. There is no retropulsed bony fragment, paraspinal mass or cord compression. 
and increased signal on T2 weighted sequences. MRI imaging sequences that are useful for identifying malignancy include short $\mathrm{T} 1$ inversion recovery sequences (STIR) and fat suppression images (6). Contrast enhanced MR is useful for evaluation of leptomeningeal spread of malignancy and extension of tumor into the paraspinal soft tissues. Multiple foci of disease, destruction of bony cortex and pedicle involvement is common and suggests a diagnosis of metastatic disease.

The most common non-malignant tumors of the spine include hemangiomas, osteoid osteoma and histiocytosis. Hemangiomas have a prevalence of $11 \%$ and are usually asymptomatic $(7,8)$. They appear as well circumscribed areas of high signal intensity on $\mathrm{T} 1$ due to their adipose content and on $\mathrm{T} 2$ due to their angiomatous component.

Osteoid osteomas are most commonly found in males between 5 and 20 years of age and commonly arise in the tubular bones such as tibia and femur. Ten percent of osteoid osteoma originate in the spine (9). They are usually present in the lumbar spine, affecting the posterior elements $(10,11)$. Involvement of the vertebral body is rare (9) and compression fractures of the vertebral body have not been reported. Osteoid osteoma demonstrates low signal intensity on $\mathrm{T} 1$ and high signal intensity on T2 weighted images, due to reactive edema around the tumor nidus (12-14). Radiography shows surrounding sclerosis. When the nidus is larger than $1.5 \mathrm{~cm}$, it is classified as a giant osteoid osteoma.

Langerhans' cell histiocytosis (LCH) encompasses a spectrum of conditions characterized pathologically by the invasion of various tissues by a pleomorphic infiltrate containing Langerhans' cells, which are normally found only in the skin and draining lymph nodes (15). The commonest form of the disease is restricted to the skeletal system (a condition previously termed eosinophilic granuloma of bone or histiocytosis $\mathrm{X}$ ). The spine is involved in approximately one quarter of patients with eosinophilic granuloma (16). In the spine, LCH most commonly affects the thoracic vertebrae, followed by the lumbar and cervical regions. The classical appearance of "vertebra plana" on plain films is present in approximately $15 \%$ of patients (17). A characteristic feature of vertebral involvement is the lack of involvement of the endplates. For this reason, the vertebrae typically regain some height once the disease becomes inactive (18). Unlike metastatic disease the posterior elements are less often involved (19). The vertebral body may collapse either symmetrically or asymmetrically. An associated paravertebral soft tissue mass is uncommon (17), although it has been reported (20, 21). MRI shows non-specific features including vertebral collapse and reduced marrow signal intensity on T1weighted sequences with increased signal intensity on T2-weighted sequences (22-25). Kaplan et al (22), in a study involving two patients, correlated the MRI changes on T1 and T2 weighted images with histological findings. They noted that levels with reduced signal intensity on T1-weighted sequences and increased signal on T2weighted sequences revealed typical histological features of LCH on biopsy, while lesions with increased signal intensity on T1-weighted sequences with normal marrow signal on T2-weighted sequences showed evidence of a non-specific healing response in the marrow spaces and trabeculae. They propose that MRI is useful not only in assessing associated reactive bone marrow and soft tissue changes, but also in assessing the activity of the vertebral body lesion, and therefore providing a guide to the optimal biopsy site.

The natural history of LCH in the spine is one of partial restoration of vertebral height following either spontaneous resolution of the disease or various treatments. Yeom et al (18) reviewed clinical and radiologic data of 38 lesions in 23 children with an average follow-up of 5.4 years and found satisfactory restoration of height in all except five vertebrae. This was not influenced by the treatment patients received, regardless of whether this was radiotherapy, chemotherapy or corticosteroids. Partial reconstitution of vertebral body height was also shown in 15 of 20 vertebral lesions in the study by Sartoris and Parker (16). The rate of healing was again unaffected by the mode of therapy but was related to the age of the patient, with the rate of healing being inversely proportional to the patient's age at presentation. Up to $85 \%$ of normal height can be achieved in some cases. Healing with fusion across the disc space is also a common feature. Some vertebrae show a "bone within a bone" appearance as they heal (3).

In our patient, the biopsy of the $\mathrm{T} 5$ vertebral body revealed the diagnosis of Langerhan's cell histiocytosis. The patient subsequently underwent a course of radiation therapy to the $\mathrm{T} 5$ vertebrae site.

In conclusion, this patient presented with a collapsed $\mathrm{T} 5$ vertebral body without constitutional symptoms and normal erythrocyte sedimentation rate and total white cell count. MRI showed low signal intensity on T1-weighted images and high signal intensity on T2-weighted images, with absence of paraspinal mass, retropulsed bony 
fragment, or cord compression. These features are characteristic of Langerhan's cell histiocytosis, but the definitive diagnosis is established by biopsy.

\section{REFERENCES}

1. Jones DA, Koval KJ, Zuckerman JD et al. Epidemiology. In Koval KJ, Zuckerman JD (eds). Fractures in the elderly. Lippincott-Raven, Philadelphia, 1998; pp 3-9.

2. Luckert B. Vertebral compression fractures: How to manage pain, avoid disability. Geriatrics 1994; 49:2226.

3. Nesbit ME, Kieffer S, D’Angio GJ. Reconstitution of vertebral body height in histiocytosis X: a longterm followup. J Bone Joint Surg (Am) 1969; 51:13601368.

4. De Roos A, Van Persijn van Meerten EL, Bloem JL et al. MRI of tuberculous spondylitis. Am J Roentgenol 1986; 147:79-82.

5. Modic MT, Feiglin DR, Piriano DW et al. Vertebral osteomyelitis: Assessment using MR. Radiology 1985; 157:157-166.

6. Stimac G, Porter BA, Olson DO et al. GadoliniumDTPA-enhanced MR imaging of spinal neoplasms: Preliminary investigation and comparison with unenhanced spin-echo and STIR sequence. Am J Roentgenol 1988; 151:1185-1192.

7. Laredo JD, Reizine D, Bard M et al. Vertebral hemangiomas: radiologic evaluation. Radiology 1986; 161:183.

8. Mohan V, Gupta SK, Tuli SM. Symptomatic vertebral hemangiomas. Clin Radiol 1980; 31:575.

9. Bridge JA, Schwartz HS, Neff JR. Sarcomas of bone. In Abeloff MD, Armitage JD, Lichter AS (eds). Clinical Oncology $2^{\text {nd }} E d$. Churchill Livingston New York, 2000; pp 2231-2233.

10. Kransdorf MJ, Stull MA, Gilkey PW et al. Osteoid osteoma. Radiographics 1991; 11:671.

11. Jackson RP, Reckling FW, Mantz FA. Osteoid osteoma and osteoblastoma. Similar histologic lesions with different natural histories. Clin Orthop 1977; 128:303-313.

12. Kawaguchi Y, Hasegawa T, Oka S, Sato et al. Mechanism of intramedullary high intensity area on
T2 weighted magnetic resonance imaging in osteoid osteoma: a possible role of Cox-2 expression. Pathol Int 2001; 5112:933-937.

13. Lefton DR, Torrisi JM, Haller JO. Vertebral osteoid osteoma masquerading as a malignant bone or soft tissue tumor on MRI. Pediatr Radiol 2001; 31:7275.

14. Spouge AR, Thain LM. Osteoid osteoma: MR imaging revisited. Clin Imaging 2000; 24:19-27.

15. Siegelman SS. Taking the X out of histiocytosis X. Radiology 1997; 204:322-324.

16. Sartoris DJ, Parker BR. Histiocytosis X: Rate and pattern of resolution of osseous lesions. Radiology 1984; 152:679-684.

17. Reddy PK, Vannemreddy PS, Nanda A. Eosinophilic granuloma of spine in adults: a case report and review of literature. Spinal Cord 2000; 38:766-768.

18. Yeom JS, Lee CK, Shin HY et al. Langerhans cell histiocytosis of the spine. Analysis of twenty-three cases. Spine 1999; 24:1740-1749.

19. Robert H, Dubousset J, Miladi L. Histiocytosis in the juvenile spine. Spine 1987; 12:167-172.

20. Poulsen JO, Thommesen P. An unusual case of histiocytosis X of the spine. Acta Orthop Scand 1976; 47:59-62.

21. Thommesen P, Bartholdy N, Bunger E. Histiocytosis X simulating tuberculosis. Acta Radiol Oncol 1983; 22:295-297.

22. Kaplan GR, Saifuddin A, Pringle JS et al. Langerhans cell histiocytosis of the spine: Use of MRI in guiding biopsy. Skeletal Radiol 1998; 27:673-676.

23. Beltran J, Aparisi F, Bonmati LM et al. Eosinophilic granuloma: MRI manifestations. Skeletal Radiol 1993; 22:157-161.

24. Lauffenberger MD, Dull ST, Toselli R. Eosinophilic granuloma of the adult spine: A case report and review of the literature. J Spinal Disord 1995; 8:243-248.

25. Haggstrom JA, Brown JC, Marsh PW. Eosinophilic granuloma of the spine: MR demonstration. J Comput Assist Tomogr 1988; 12:344-345.

26. Modan-Moses D, Weintraub M, Meyerovitch J et al. Hypopituitarism in Langerhans cell histiocytosis: Seven cases and literature review. J Endocrinol Invest 2001; 24:612-617. 